\title{
GONZALO ROJAS: TRANSCRIPCIÓN DE UN BALBUCEO SOBRE EL POEMA "CARBÓN"
}

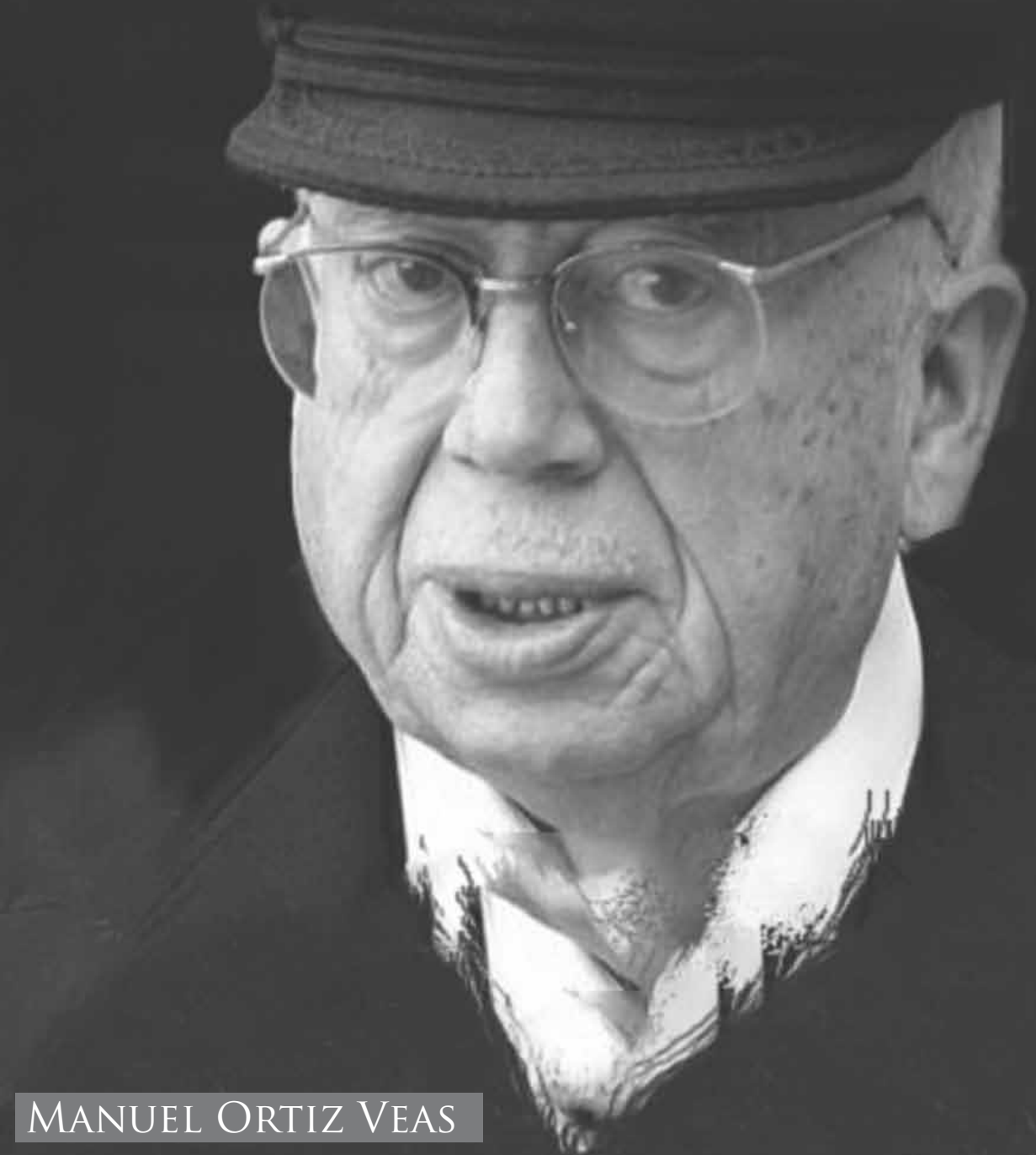

Periodista. Magíster en Comunicaciones (Universidad de Québec, Montreal, Canadá).

Académico Universidad de La Frontera. Temuco, Chile. E-mail: maortiz@udec.cl 


\section{CARBÓN}

Veo un río veloz brillar como un cuchillo, partir mi Lebu en dos mitades de fragancia, lo escucho, lo huelo, lo acaricio, lo recorro en un beso de niño como entonces, cuando el viento y la lluvia me mecían, lo siento como una arteria más entre mis sienes y mi almohada.

Es él. Está lloviendo.

Es él. Mi padre viene mojado. Es un olor

a caballo mojado. Es Juan Antonio

Rojas sobre un caballo atravesando un río.

No hay novedad. La noche torrencial se derrumba como mina inundada, $y$ un rayo la estremece.

Madre, ya va a llegar: abramos el portón, dame esa luz, yo quiero recibirlo antes que mis hermanos. Déjame que le lleve un buen vaso de vino para que se reponga, y me estreche en un beso, y me clave las púas de su barba.

Ahí viene el hombre, ahí viene embarrado, enrabiado contra la desventura, furioso contra la explotación, muerto de hambre, allí viene debajo de su poncho de Castilla.

Ah, minero inmortal, ésta es tu casa de roble, que tú mismo construiste. Adelante: te he venido a esperar, yo soy el séptimo de tus hijos. No importa que hayan pasado tantas estrellas por el cielo de estos años, que hayamos enterrado a tu mujer en un terrible agosto, porque tú y ella estáis multiplicados. No importa que la noche nos haya sido negra por igual a los dos.

-Pasa, no estés ahí

Mirándome, sin verme, debajo de la lluvia. 
C STA entrevista se realizó al poeta Gonzalo Rojas, en Roble 1051-, en la casa de los padres de su esposa Hilda, que era también el hogar de ambos.

El título fue sugerido por él y de su puño y letra hubo correcciones a sus propias palabras habladas para readecuarlas al lenguaje escrito.

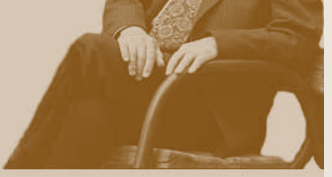

Ambos, entrevistador y poeta, no se reencontraban desde hacía más de 7 años, por vivir en el exilio.

En el momento de la entrevista el poema “Carbón” cumplía 40 años.

-“Carbón” cumple, este 1989, 40 años. Si usted tuviera que hacer la exégesis de este "poema mayor". ¿El sentido es el mismo o usted cree que ha cambiado?

La idea del sentido en poesía -Manuel- no es fácil de resolver. Es siempre una grave, una intensísima preocupación de los poetas, quienes efectivamente tenemos que descifrar el sentido. Un sentido a veces desde el sonido mismo puesto que la poesía es ese cuento, y las palabras conllevan un sonido o un "zumbido" -como me gusta a mí decir-y un sentido. A veces el sentido, como te digo, se ofrece desde la vivacidad fónica, desde el soplo, desde el neuma, como decían los griegos. Así, pues, y otras veces no... A veces el sentido se escurre, se enigmatiza -aunque no existe el verbo te lo invento ahora mismo-, se cierra, se hace críptico; y la verdad es que cuando uno escribe (porque este poema, como tú señalas, tiene 40 años ya de haber sido escrito después del movimiento de la mano y de la imaginación frente a un papel), cuando uno escribe, la trama enigmática del sonido y del sentido, yo diría que intentan perdurar, intentar ser, intentan ser -pero bien subrayado ese "SER"-...de lo que se trata es de "mostrar", como decía Pound, y yo diría un "mostrar" el "SER", un "mostrar" en EL SER mismo.

De ahí que si me preguntas. ¿Tiene el mismo sentido este poema al cabo de 40 años que cuando fue escrito? Yo digo: es que nunca tuvo otro sentido que el mismo sentido que por lo menos yo tramé cuando urdí estas palabras en relación con unos recuerdos, con unas vibraciones afectivas, con unas... adivinaciones en lo que me parecía ser la relación padre-hijo o la relación hombre-tierra mejor. 
Así pues, no te sé decir. Di una larga vuelta para decirte no te sé decir. Lo que afirmo, es que creo -desde mi punto de vista-que no varió el sentido. El sentido se dio desde el principio. Es el mismo.

-Ahora... entrando en el poema mismo: ¿Por qué el "cuchillo"?, cuchillo que aparece también en otros poemas suyos.

He contado en otras oportunidades, que cuando jovencito yo, sobre mis 18 años $-17 \ldots 18$ años-, cuando empezaba a escribir, sin que... sin que eso fuera una liturgia o un -qué sé yo- un acto semiocultista, yo hacía una operación curiosa: disparaba un cuchillo que yo tenía.

Junto con mis lápices y mis papeles solía haber un cuchillo encima de mi mesa. Y ese cuchillo era fino, era vivo; y a mí me parecía que ese cuchillo era capaz de entrar, más que en la madera encima de la cual yo escribía, de entrar en la famosa "realidad". Entonces yo disparaba -hacía esta operación un poco... un poco loca-, disparaba un cuchillo, mi cuchillito, contra la mesa de tabla pobre en la que escribía, y si ese cuchillo "vibraba", piensa tú, repara en esa idea: "la vibración"-vibración, ritmos, todo eso junto-; si ese cuchillo "vibraba" (bueno yo me ponía a cierta distancia del cuchillo para empezar, no tenía gracia clavar un cuchillo con fuerza de muchacho encima de una mesa. No, no)...

Yo disparaba como quien va a desafiar: el Sí o el No de una opción, la opción de decir el mundo. Disparaba, es decir, a ver si acertaba o no acertaba; es decir, desafiaba, es decir, no partía de esa locura que se llama confianza, que los letrados y los señores pseudocientíficos creen que es el centro de la palabra o del pensamiento artístico, la exactitud. Nada con la exactitud. Sin embargo, yo desafiaba este proyecto y disparaba mi cuchillo. Si el cuchillo vibraba y entraba en la madera, eso quería decir que estaba mi cabeza también a punto y mi palabra estaba suficientemente fresca como para salir en toda su lozanía; pero, si el cuchillo se resbalaba... resbalaba... entonces quería decir que no.

Es decir, le estaba asignando sin duda este cuchillo entrando en el madero -en la madera-, le estaba asignando un poder mágico, no lo oculto. Entonces este cuchillo anduvo siempre conmigo, no el cuchillo en cuanto a andar conmigo, tú me entiendes, la idea, la imagen.

La imagen del cuchillo mía no es la imagen del cuchillo de Borges, por ejemplo. Borges habla mucho de cuchillos, pero aludiendo a sus cuchilleros de los arrabales de Buenos Aires. También habla del cuchillo en un sentido tal vez más abierto, tal vez más simbólico. Para mí el cuchillo guarda relación 
con el enigma mismo de escribir. Ahora, el cuchillo es cortante -Manuel-. El cuchillo es cortante, es pericoloso dicen los italianos, es peligroso. Esto de escribir es un riesgo, es una apuesta, es un desafío. No es raro entonces, que el hablante en mi caso, cuando dispara el cuchillo sobre la mesa para que entre en vibración con el mundo, esté desafiando la opción de "SER", nada menos que eso. Así pues este cuchillo no es un instrumento filudo y cortante y nada más, sino que contiene esa otra dimensión de un pensamiento acerado que quiere entrar en un trato fresco, vivo, intenso con el "ser".

Así, no te extrañe cuando el hablante dice: "VEO UN RÍO VELOZ BRILLAR COMO UN CUCHILLO", se pudo haber dicho "brillar como un espejo". Pero no, mi señor. Se trataba de que brillara como "un cuchillo". Es decir -no se trataba... aquí no había nada forzado-, aquí jugó lo espontáneo su juego... juego espontáneo de la visión de un río que efectivamente existe, sólo que está trascendido; es el mismo río que existe. Hay una transfiguración con toda poesía que quiere ser más honda, supongo.

"VEO UN RÍO VELOZ BRILLAR", ahora si tú ves el adjetivo "veloz" respecto de río no es ninguna novedad, es un epíteto más. Los ríos suelen ser veloces, a veces son más mansos, pero éste era muy veloz. Ahora si yo veo un río veloz, estoy viendo, a la luz de la memoria, una visión vertiginosa como va a ser toda la que ofrece este poema, entiendes. Este poema no está construido desde la tranquilidad... del equilibrio. Está construido desde el equilibrio y desde la inarmonía a la vez.

Entonces: "VEO UN RÍO VELOZ"... y luego "BRILLAR COMO UN CUCHILLO" y asociado con cuchillo, no te extrañe que en el primer verso, al cierre de la primera línea el hablante ponga "PARTIR". Esta idea de partir también es muy importante (perdón que te explique largo, es que me parece que si tienes la opción de consultarme sobre este texto, es bueno que yo diga algunos puntos de vista míos). "Partir" implica sin duda separar, cortar; pero, partir, también significa salir... y aunque no guarda relación estrecha con la idea de parto, cuando tú sales de la madre, te desprendes de esa luz uterina, entonces lo que tú haces es partir. Hay otro poema mío en el cual -pero de unos 30 años o algo así posteriores a éste- en el cual se dice: "parto soy, parto seré, parto, parto, parto"; es decir, el estar naciendo siempre.

Te digo todo esto aunque sea abusivo, porque (abusivo a que estoy empleando tu tiempo más allá de lo que tú pensabas tal vez)... porque quiero reparar o hacerte pensar un poco en que la primera línea puede ofrecer mucho más de lo que la gente cree. Es que no es un hilo instrumental, esto no es un ejercicio con exactitudes o aproximaciones. Este es un juego mayor. 
"VEO UN RÍO VELOZ BRILLAR COMO UN CUCHILLO", COMa, "PARTIR". Luego pregunta ¿qué es lo que se parte?: "MI LEBU EN DOS MITADES DE FRAGANCIA". Luego no hay que ser ningún despierto para advertir que primero está el ojo que ve "Un río veloz brillar como un cuchillo", y casi hiere al ojo la luz de ese río por "Lo cuchíllico", por "lo cuchíllico" que es ese brillo. "VEO UN RÍO VELOZ BRILLAR COMO UN CUCHILLO, PARTIR MI LEBU EN DOS MITADES DE FRAGANCIA", mira como entra en trato de inmediato el otro sentido. Yo soy un animal poético-fisiológico. En mi opera muy frescamente, muy dinámicamente y desde siempre ahora lo veo a la distancia de mis años y hace 50 que empecé a escribir... este poema tiene más de 40 años ya te lo dije-... yo veo como siempre hice funcionar no un sentido, ni los cinco sentidos, sino... qué sé yo 20,50 sentidos.

-Perdón. La pregunta siguiente. Impresiona en "Carbón" la palabra viva; o mejor, me explico... cómo las abstractas palabras adquieren "vida" y las sentimos, vemos, oímos-escuchamos, olemos...

Ahí está el gran juego...

-Ese juego de nuestros sentidos -sus sentidos- que nos permiten participar (ahí yo huelo a comunicación verdadera entre hablante y lector) la -su vivencia de estar en Lebu y a ese cruce de tiempo (que nos hace aún más partícipes y pienso en Einstein y la relatividad) y espacios... "veo un"... "lo huelo"... "como entonces", "cuando"...

Correcto. Estás pegando en el clavo. Muy bien. Aquí está lo sensóreo múltiple en la mostración de esa experiencia de haber vivido en Lebu, pero a la vez de ver un RE-LEBU desde ahora. Es decir -tú dijiste una cosa muy importante-, hay un cruce de tiempos, de temporalidades en este poema: "MI LEBU EN DOS MITADES DE FRAGANCIA", (las mitades de fragancia serían motivo de explicación también) "LO ESCUCHO",...entra la oreja... "LO HUELO", entra el otro sentido; "LO ACARICIO, LO RECORRO EN UN BESO DE UN NIÑO COMO ENTONCES".

Ese "ENTONCES" se le entrega al oyente o al lector como si él lo conociera, pero se explica cuando se señala: "CUANDO EL VIENTO Y LA LLUVIA ME MECÍAN", ese es "entonces". "LO SIENTO", y ahora viene una línea la quinta, la última de la primera estrofa que es muy material: "COMO UNA ARTERIA"... -el río es una arteria, no se ha desprendido el río de la cabeza del niño-. "COMO UNA ARTERIA MÁS ENTRE MIS SIENES Y MI ALMOHA- 
DA". Tengo mis arterias, pero tengo las arterias del río. ¿Se entiende, no? Otra preguntita por favor.

-Sí. Gracias. Se refiere a la segunda estrofa: "es el" es su padre que vuelve, pero a la vez puede ser mi padre o el progenitor de cualquier lector-oyente que vuelve. Y vuelve a su casa y vuelve del trabajo, pero como un hijo pródigo"... ¿Una paradoja dramática-lírica a la vez?

Claro. El padre vuelve de un trabajo terco, duro como es el de los mineros. Aquí no hay una celebración del padre, como lo dice yo no sé cuál de los estudios que son tantos ya, que se han escrito sobre esta pieza mía -esta vieja pieza lírica-; no hay una celebración del padre. Hay aquí un diálogo con el padre, un intra diálogo con él. Pero a la vez, hay como tú señalabas antes, hay dos tiempos: el tiempo de la distancia y el tiempo de la aproximación. El tiempo del distanciamiento cuando se dice: "ES ÉL". Se establece el distanciamiento y se señala luego cuando se dice: "ESTÁ LLOVIENDO". Pero también está la interiorización de esa presencia. Tal vez aquí, por aquí pudiera explicarse la virtud de este -la virtud quiere decir: la fuerza, la luz, la gracia-... de este texto, ¿no? En el cruce de esas dos dimensiones temporales.

"ES ÉL. ESTÁ LLOVIENDO". "Es él”; esa reiteración también es importante de señalar. Y ahora recién se dice: "MI PADRE VIENE MOJADO", o sea, contra el patetismo del "mi padre viene mojado" el distanciamiento. ¿Viste?

Voy a repetirte esta idea. Siempre pensé desde muchachito, cuando empecé a escribir -desde cuando empecé a escribir mis primeros versos-, que no había que caer en la miseria del "pathos", del sentimiento por el sentimiento o sentimentalismo y que había que desplazar el juego de lo patético al distanciamiento y del distanciamiento a lo patético. No es que uno elimine al "pathos". El "pathos" es el sentimiento, la sensibilidad, la luz afectiva, sensible, indispensable para el trabajo poético; la emoción, todo lo que tú quieras, toda la parentela de la afectividad; pero, a la vez, para que tú construyas, es decir, consigas una forma, tienes que enfocar bien y el enfoque implica distanciamiento. ¿Se ve?...

-Pero está también ahí el juego de la empatía. El meterse psicológicamente en el lugar del otro...

Claro. Está la empatía, pero está a la vez el apartarse... que es el verlo desde 
lejos... distanciamiento: "ES ÉL. ESTÁ LLOVIENDO". Suponte que la segunda estrofa en vez de empezar así, hubiese empezado así: "era mi padre que venía mojado". ¿Qué horror! ¿Me entiendes? En cambio, mira como cobra vivacidad esto después que se ha presentado la idea... el río, toda esta conexión de lo sensoreo, de un niño que persiste en ser un niño puesto que todavía en él la arteria del río anda "ENTRE SUS SIENES Y SU ALMOHADA". Después de eso, el hablante se desplaza y dice: "ES ÉL", va a mostrar al padre; "ES ÉL. ESTÁ LLOVIENDO". Le da el ámbito.

Llover-Manuel- no significa el mero... como se dice la mera situación física de un estar cayendo agua. Llover en esta poesía de Gonzalo Rojas tiene un sentido mucho más hondo. (Y ya alguna vez me has oído decir que un verdadero poeta registra un sistema de pensamiento como los filósofos o como los científicos, pero desde lo imaginario sin duda. Un sistema imaginario, un sistema de imaginación). Además, si tú lees con cuidado distintos versos míos, distintas líneas mías de distintos plazos, te vas a encontrar con frecuencia, aun en los poemas más abstractos, con la idea de lluvia o la mención de lluvia o con la determinación de llover.

Llover es germinar, llover es lo húmedo. No es solamente la lluviecita del sur de Chile por mucho que sobre el Golfo de Arauco cayera la lluvia tanto como se sabe, no, no. Estaríamos haciendo una mera evocación menor. Ese "el estar lloviendo", ese "ESTÁ LLOVIENDO"... es muy importante. Y eso no lo ha dicho nunca un crítico, porque los críticos en general no entran en el gran juego. Pero "ESTÁ LLOVIENDO" quiere decir algo más que lo higrométrico. ¿Cómo se dice?..., que la dimensión exclusiva de un fenómeno físico llamado lluvia. No. "ES ÉL. ESTÁ LLOVIENDO. ES ÉL. MI PADRE VIENE MOJADO"; ahí sí que te creo que entra la lluvia, en el mojado. La primera vez no. "ES UN OLOR A CABALLO MOJADO". Se va afinando la visión, más y más.

Por otra parte repara en el juego de la determinación ES. Ahora, ¿por qué el hablante emplea el término "ES” tanto? “ES’ ÉL”. Después “"ES' ÉL”... mira: “ES’ ÉL. ESTÁ LLOVIENDO". Luego “"ES' ÉL”. Después “"ES' UN OLOR A CABALLO MOJADO". "ES' JUAN ANTONIO ROJAS". "ES"... el verbo del "ser". Ya te hablaba yo de la importancia que se le asigna siempre en mi poesía al "ser” ¡Ah! "ES ÉL. ESTÁ LLOVIENDO. ES ÉL. MI PADRE VIENE MOJADO. ES UN OLOR A CABALLO MOJADO"; o sea, se aproxima a todo, desde la sensación olfativa, olfatoria: "ES UN OLOR A CABALLO MOJADO. ES JUAN ANTONIO ROJAS SOBRE UN CABALLO ATRAVESANDO UN RÍO. NO HAY NOVEDAD"... un río, ahora ya no es el río Lebu, es un río, es un río mucho más abierto en el tiempo infinito del hombre y de los hombres. 
"ATRAVESANDO UN RÍO. NO HAY NOVEDAD", es una frase que te pareciera de la conversación, esa yo la empleé con toda intención -recuerdo- para quitarle, para restarle patetismo. Justamente, verdaderamente el término es meramente coloquial. "NO HAY NOVEDAD". También "ESTÁ LLOVIENDO", es un término coloquial. "ESTÁ LLOVIENDO"... bueno... "NO HAY NOVEDAD. LA NOCHE TORRENCIAL SE DERRUMBA COMO MINA INUNDADA, Y UN RAYO LA ESTREMECE".

Esas son las seis líneas. Sé que se han escrito cosas sobre esas seis segundas líneas, seis líneas de la segunda estrofa. No sé si tú has leído algo. No interesa lo que han escrito sobre uno, sino lo que a ti te nace decir frente a este texto.

-Y luego esta tercera estrofa. El diálogo directo, personal con la madre. El "desplacentado" hijo ( $y$ usted es el creador de esa bellísima palabra-concepto... todos somos desplacentados... yo jamás lo pensé) que le habla a su madre de su padre -La familia original: el trío, padre-madre-hijo-: ... "YA VA A LLEGAR”... "YO QUIERO RECIBIRLO ANTES QUE MIS HERMANOS”...

Claro. Entonces claro. La tercera estrofa nos lleva ya a un cuadro si tú quieres dramático. Lo primero parecía lírico. ¿No? Parece lírico eso: "VEO UN RÍO VELOZ...". Lo segundo parece un poco cuento porque viene el padre con argumento y todo: "ES ÉL. ESTÁ LLOVIENDO. ES ÉL. MI PADRE VIENE MOJADO. ES UN OLOR A CABALLO MOJADO”. Se ve el río... se ve que el hombre está pasando por encima del río todo mojado... pero ahora se crea una situación dramática. $\mathrm{Y}$ esto es interesante porque en realidad $-\mathrm{y}$ creo lo dice uno de los estudios que te estoy entregando-, en realidad en la vieja poesía española y de otras partes del mundo la relación padre-hijo se dio siempre más en lo dramático; en lo que se llamaba la parte teatral y lo dramático, que en lo lírico. Aquí simplemente el hablante rompe y dice: "MADRE, YA VA A LLEGAR"; -sin patetismo- "ABRAMOS EL PORTÓN". Abrir el portón, claro todo el mundo entiende lo que es eso. No es una puertecilla chica, sino un portalón de las casas viejas, por donde entraban los caballos y entraban los animales junto con entrar la gente... "MADRE, YA VA A LLEGAR". Ese "ya va a llegar" es la momentaneidad, la instantaneidad bien capturada según parece. "MADRE, YA VA A LLEGAR: ABRAMOS EL PORTÓN"... mira la decisión del muchacho, para decirle eso a la plasmadora, a la creadora. "DAME ESA LUZ"... ese es un término muy del país de Chile. "ESA LUZ", para indicar la lámpara. No se dice dame esa lámpara. Habría sido amanerado. El hablante dice intencionalmente como habla su 
pueblo: "DAME ESA LUZ", -ves- "YO QUIERO RECIBIRLO ANTES QUE MIS HERMANOS. DÉJAME QUE LE LLEVE UN BUEN VASO DE VINO PARA QUE SE REPONGA". -Dichos del habla común- "Y ME ESTRECHE EN UN BESO, Y ME CLAVE LAS PÚAS DE SU BARBA".

Aquí no hay palabras elegidas, selectas, te quiero decir yo... términos que se acomodan y se ajustan desde un lenguaje conversacional; y luego, otra vez el hablante -piensa tú en la cuarta estrofa- se aparta y mira como una cámara que mirara, no cierto...

-Sí, como una cámara que mirara... al hombre, al ser humano que siempre olvidamos y que usted nunca olvida. Y usted dice: "AHÍ VIENE EL HOMBRE”... del trabajo... "DEBAJO DE SU PONCHO DE CASTILLA”.

“AHÍ VIENE”... Sí. Claro. Pero espérame. Te estoy diciendo la cuarta estrofa en relación con la idea de, del yo y de la cámara, ¿no? Yo "VEO UN RÍO VELOZ"... "AHÍ VIENE EL HOMBRE". Es una cámara fría la que está tomando esto. ¿Me entiendes? Aquí hay un preanuncio de algo que ahora en mí poesía de los últimos años se ha dado apreciablemente... una trama más bien fílmica. Es muy curioso esto; es como si hubiera desplazado la oreja hacia el ojo, como lo ha dicho alguien a los periodistas el otro día.

"AHÍ VIENE EL HOMBRE, AHÍ VIENE EMBARRADO, ENRABIADO CONTRA LA DESVENTURA, FURIOSO CONTRA LA EXPLOTACIÓN. MUERTO DE HAMBRE. ALLÍ VIENE"... la segunda vez dice "ALLÍ". La primera vez dice "AHÎ". O sea, el allí está más lejos en español. "ALLÍ VIENE DEBAJO DE SU PONCHO DE CASTILLA".

Fíjate que el espacio también tiene dos dimensiones: lo momentáneo, lo que está próximo; y lo que está lejos. Entonces en ese juego dual, en ese vaivén pendular de los tiempos y de los espacios -pienso yo- que está la virtud expresiva de ese poema.

¿Qué otra pregunta por tu lado?

-Es relación por supuesto con la quinta estrofa. Hay ahora un diálogo personal con el padre. Le habla el hablante al padre y le dice: "AH, MINERO INMORTAL"...

Ahora sí. Le habla a ÉL.

-Lo "INMORTAL", que permanece, que aún vive y no muere, que está siempre vigente. 
Claro. El minero no ha muerto. Como el río no ha muerto. Como el río sigue siendo "UNA ARTERIA MÁS ENTRE MIS SIENES Y MI ALMOHADA". El padre está en lo suyo, ¿no? Ahora, el riesgo del adjetivo inmortal. Yo me acuerdo muy bien cuando escribí (aunque era tanto más joven que ahora... ahora soy viejo y entonces era un hombre muy nuevo y muy lozano todavía) y reparé el riesgo de usar ese adjetivo "INMORTAL". El adjetivo decía Huidobro, con sabiduría: "cuando no da vida mata". Entonces yo no tuve -sin embargo- ningún otro designio posible, ninguna otra palabra, ningún otro vocablo en el español para situar lo que quería, sino "INMORTAL". Porque se trata justamente de que este padre perdure, perdure... persista.

“AH, MINERO INMORTAL, ÉSTA ES TU CASA DE ROBLE”... El roble es un material, una madera muy del país y muy del mundo para construir casas. Una madera... una casa de madera. "Casa de palo", de madera, no de "material" como dice la gente. "AH, MINERO”... además corresponde a una realidad biográfica.

"AH, MINERO INMORTAL, ESTA ES TU CASA DE ROBLE, QUE TÚ MISMO CONSTRUISTE". Ahora esta "casa" no es meramente -otra vez vuelvo sobre mi objeción tenaz a la exactitud que me horroriza y me fastidia infinitamente- esta casa es más que la casa. ¿¿Se entiende? No es la casa de palo pobre... eso es; pero también, es la casa mayor, es decir, "la casa fundadora". Si tú quieres de una dinastía, en el mejor sentido.

"AH, MINERO INMORTAL, ÉSTA ES TU CASA DE ROBLE, QUE TÚ MISMO CONSTRUISTE. ADELANTE: -otra vez la inmediatez- TE HE VENIDO A ESPERAR, YO SOY EL SÉPTIMO DE TUS HIJOS”... -éramos ocho y yo era el séptimo- "YO SOY EL SÉPTIMO DE TUS HIJOS", y luego se abre la conjetura adentro del diálogo y se dice: "NO IMPORTA" -y qué riesgo había al usar esto... usar la conjetura adentro del mismo -como se dice-, adentro del diálogo tan fraterno con el padre- "NO IMPORTA QUE HAYAN PASADO TANTAS ESTRELLAS POR EL CIELO DE ESTOS AÑOS”. Se abrió enteramente esto. Se abrió la bóveda, ¿no es así?... como cuando tú miras las estrellas, la noche. Se abre todo y ya no tienes tú la limitación del tiempo terco.

"NO IMPORTA QUE HAYAN PASADO TANTAS ESTRELLAS POR EL CIELO DE ESTOS AÑOS, QUE HAYAMOS ENTERRADO"... es buena pienso yo, ahora que la estoy mirando como si yo fuera un lector reciente de este poema viejo mío, es buena..., es bueno el contrapunto entre "estrellas" por un lado y "enterrado" por el otro lado, ¡ah! Alguna vez he escrito que mi cielo mío "es un cielo abajo". Es el cielo profundo, parece que aquí funcionó -funcionó- la mente del hablante de esta manera cuando escribió esto: "NO IMPORTA QUE HAYAN PASADO TANTAS ESTRELLAS POR EL CIELO DE ES- 
TOS AÑOS”, ... y tú vez volando las estrellas cuando lees esta línea... "QUE HAYAMOS ENTERRADO A TU MUJER EN UN TERRIBLE AGOSTO, PORQUE TÚ Y ELLA ESTÁIS MULTIPLICADOS". Y luego piensa, repara que el hablante dice ahí: "NO" y ese "no" queda colgado. No es una arbitrariedad que ese "NO" quede colgando en esa línea. Es porque ese "NO" es una cerrazón muy honda y una apertura también.

"NO IMPORTA QUE LA NOCHE NOS HAYA SIDO NEGRA POR IGUAL A LOS DOS". Entonces el hablante se retira y lo echa adentro si tú quieres hablar así, al que estaba afuera... que era este pobre progenitor de uno y le dice: “-PASA"... no puede ser menos afable en cuanto a modo de decir, pero tampoco no puede dejar de reconocerse que hay aquí un trato, un trato con el padre. Ese punto final lo lanza con el diálogo. Hay aquí una rayita propia del diálogo -que se dice- propia del teatro, como también en la prosa, en la narrativa: “-PASA, NO ESTÉS AHÍ MIRÁNDOME, SIN VERME, DEBAJO DE LA LLUVIA".

Eso es casi un prosaísmo, pero vamos viendo qué prosaísmo. "PASA, NO ESTÉS AHÍ" le dice una madre a un hijo o un niño a otro hermano o quien sea a otro. Éste le dice al PADRE que andaba en la fantasmalidad de sus recuerdos: "PASA, NO ESTÉS AHÍ MIRÁNDOME, SIN VERME"... cuidado con no remarcar la diferencia entre mirar y ver. Tú no me ves, me miras no más: "No estés ahí sin verme debajo de la lluvia". Soy yo el que te veo. Habría que entender esto. ¿Me entiendes? Entonces sin caer en esos abusos de confianza con la interpretación y con esos equívocos tan lamentables, yo creo que por aquí anda una idea que después yo la presenté o lo propuse en otros textos míos; también enlazados con la poesía de abolengo, jah!, con la idea de que "el hijo es el padre", que no es una idea mía. Esa idea -por lo demás- es una idea vieja como la Tierra. "El hijo es el padre" y eso lo... y eso lo descubre uno cuando es mayor. Porque este poema -no sé si está escrito en algunos de los estudios que se han formulado sobre "CARBÓN"-, este poema no es el de un muchachito, es el de alguien que pensó, que pensó frente a la cordación padre-hijo, engendrante-engendrado.

-Lo que impresiona es ese "cordón umbilical paterno". Cordón (que al igual que el materno, aunque algunos/as no lo crean) que no se rompe nunca.

Es muy importante. Es importante lo que estás diciendo; "cordón umbilical paterno" es lo más obvio que se puede decir, porque en general los poetas hablan o le dicen cosas a la madre, a aquella que efectivamente lo llevó a 
uno en su vientre, en su seno y que estuvo atada a uno en profundidad y veracidad. El padre no. Entonces son pocos los poemas al padre dados en esta intensidad y en esta conexión fisiológica, es el padre el que está presente. Eso no quiere decir que yo no le haya escrito un par de versos a mi madre. Este es el padre, la figura paterna.

En realidad creo que he hecho, o se hizo... no voy a decir "he hecho". Se hizo una buena contribución a la literatura o a la poesía en la que se muestra la transfiguración de la creatura humana desde el correlato padrehijo... hijo-padre.

-Y para terminar y muchísimas gracias por concederme esta entrevista. Quiero hacer una comparación con la "música mayor": Charles Dutoit, director de la orquesta sinfónica de Montréal, decía que la música, a la vez más fácil y más difícil era la de Mozart... "Les gusta hasta a los niños pero es perfecta y dificilísima". Yo encuentro que el "poema" -y lo escribo mayúscula "CARBÓN"-es facilísimo y está escrito con palabras tan simples como las notas musicales que son también tan simples: pero es a la vez un poema tan difícil, complejo, exacto (yo sé que usted detesta la perfección y la exactitud, pero "Carbón" tiene las palabras justas, precisas... ni una más... ni una menos). Además y continuando en esta comparación con la "música mayor": Leonard Bernstein, otro de los grandes directores del presente siglo, decía refiriéndose a Beethoven: "su música es la más rica en armonía... trabajaba cada nota hasta que él encontraba la precisa... y cada nota era la perfecta"; en "Carbón", como "poema mayor" y obra completa, me parece encontramos lo mismo... la armonía es la reina y hasta el ritmo-que es siempre tan importante y fundamental- se ve un poco opacado. En mi opinión, en "Carbón" el personaje centralísimo es definitivamente "la palabra" que, como las algas se ajusta, se adapta perfectamente a las ondas y al oleaje de la "lengua"-"mar".

Yo creo que también ahí estás apuntando a algo central, porque siempre en el trabajo que yo he venido haciendo "el lenguaje" es el PERSONAJE, si cabe el término. El lenguaje es lo mayor. No es el recuerdo -que como que podría haberse vertido de otra manera... un recuerdo, un padre, un niño... Lebu-; sino que es el TEMPO, el tiempo justo, el ritmo verdaderamente válido, el respiro como me gusta decir a mí. El respiro asfixia prácticamente para poder mostrar lo único necesario. Y claro, tú tienes razón. Yo todavía sigo pensando que aquí no sobra ningún vocablo. Este poema fue escrito... ahora si me preguntas ¿cómo lo escribí?, ¿a qué velocidad? Todavía me acuerdo. Lo escribí una noche sin mucho apuro y sin corrección mayor. 
Pero sin duda andaba por dentro de mi seso ya este ejercicio. Por eso es que salió con tal lozanía inclusive. Hay otros poemas en los que yo he trabajado mucho y en éste no. ¿Qué más puedo decirte?

-Muchas gracias. 